\title{
Geopolítica Ambiental: A construção ideológica do Desenvolvimento Sustentável [1945-1992]
}

\section{Leandro Dias de Oliveira}

\section{(2) OpenEdition \\ 1 Journals}

\section{Electronic version}

URL: http://journals.openedition.org/espacoeconomia/8437

DOI: 10.4000/espacoeconomia.8437

ISSN: 2317-7837

\section{Publisher}

Núcleo de Pesquisa Espaço \& Economia

\section{Electronic reference}

Leandro Dias de Oliveira, "Geopolítica Ambiental: A construção ideológica do Desenvolvimento Sustentável [1945-1992] », Espaço e Economia [Online], 15 | 2019, Online since 03 November 2019, connection on 05 November 2019. URL : http://journals.openedition.org/espacoeconomia/8437 ; DOI : 10.4000/espacoeconomia.8437

This text was automatically generated on 5 November 2019 .

(C) NUPEE 


\section{Geopolítica Ambiental: A construção ideológica do Desenvolvimento Sustentável [1945-1992]}

Leandro Dias de Oliveira

\section{Link - Editora Autografia}

https://www.autografia.com.br/produto/geopolitica-ambiental-a-construcaoideologica-do-desenvolvimento-sustentavel-1945-1992/ 


\section{Capa}

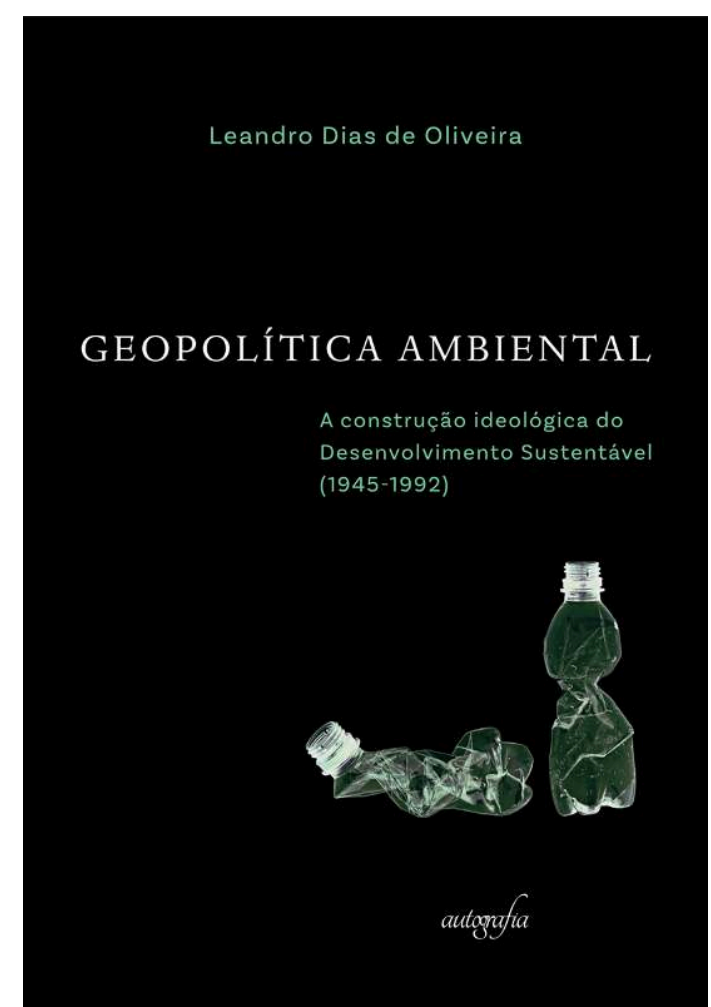

«O que escondem e o que revelam esses acontecimentos efêmeros sobre as dinâmicas política, social e econômica do mundo contemporâneo? A ECO-92 - como passou a ser chamada a CNUMAD - e o Fórum Global constituíram um megaevento, num simulacro espacial embora nada tenha sido edificado para a sua realização.

Um livro indispensável para compreender o tempo e o espaço conectados para o simulacro da geopolítica internacional que criou o lema do desenvolvimento sustentável, ocultando as contradições e conflitos reais e criando o simulacro de que a resolução se dará pelo mercado ».

Arlete Moysés Rodrigues - Professora Livre Docente da UNICAMP

«Desenvolvimento sustentável não é uma concepção elaborada para defender o meio ambiente. Ao lado de desenvolvimento local, planejamento estratégico, etc., foi instrumento de imposição do projeto neoliberal, sobretudo a partir do Consenso de Washington, onde se delineou o domínio das economias e dos territórios dos países periféricos. O nível de imposição era tão intenso que nenhum documento da ONU após a Rio-92 podia ser impresso sem referenciá-lo.

Sua evolução precisou ser analiticamente desconstruída e é isso que este livro representa. É uma obra de referência que oferece uma leitura crítica para todos os que defendem o meio ambiente ».

Floriano Godinho de Oliveira - Professor Associado da UERJ

\section{Apresentação}

2 Slavoj Žižek afirma que parece mais fácil para a população mundial imaginar o "fim do mundo", com a visão assombrosa de um colapso da natureza que ocasione a destruição da vida na Terra, do que uma mudança muito mais modesta no modo de produção, como se houvesse uma verdadeira impossibilidade de implementação de uma alternativa séria e real ao sistema capitalista. Assim como a sociedade capitalista 
avançada nos fornece este exemplo categórico de ideologia, nos evidencia também a existência de um violento e incontestável estigma, de caráter transnacional, que podemos denominar como crise ambiental, marcada principalmente por uma ordem de escassez de recursos naturais e pela crescente poluição em suas mais diversas formas, acrescidos pela incapacidade de resolução imediata dos anátemas ecológicos engendrados pelo próprio sistema político-econômico vigente.

3 A solução geopolítica e geoeconômica foi construída nas discussões de conclaves internacionais e sintetizada sob a concepção de desenvolvimento sustentável, enigmaticamente definido como um novo modelo capaz de promover a satisfação das necessidades presentes e futuras da humanidade. Os esforços para sua efetivação devem compreender as mais diversas escalas, do global ao local, independentemente da situação de desenvolvimento econômico e também sua promoção deve amalgamar os mais diversos atores sociais, desde governantes e empresários até trabalhadores e estudantes. Indiscutivelmente, a concepção de desenvolvimento sustentável tem conseguido conquistar fiéis defensores e tornou-se terminologia obrigatória em ambientes empresariais, industriais, acadêmicos, midiáticos ou governamentais. Assim, esta adequação do desenvolvimento desponta atualmente como novo padrão de organização econômico-social para todos os países (centrais e periféricos), baseado na proposta de uso racional dos recursos naturais para a satisfação das necessidades das gerações presente e futura.

4 O objetivo central deste livro é realizar uma análise da trajetória da concepção de desenvolvimento sustentável, a partir do aqui intitulamos Geopolítica Ambiental, que pode ser sintetizada como o processo contemporâneo de disputa dos Estados-maiores pelo controle da natureza-território. Dentro de um grande amálgama que pode ser entendido como a relação sociedade-natureza na contemporaneidade, este estudo está situado no debate sobre a construção e celebração da ideologia do desenvolvimento sustentável em caráter global. Neste sentido, o foco na Conferência das Nações Unidas sobre Meio Ambiente e Desenvolvimento (Rio de Janeiro, 1992) é primordial, tanto pela celebração por meio de seus documentos - especialmente a Agenda 21 - quanto pela ilusão de comunhão de interesses por meio de um verdadeiro simulacro de consenso entre centro e periferia, diplomatas e movimentos sociais, ricos e pobres.

5 Este livro que agora apresentamos apresenta três capítulos iniciais que podemos assim sintetizar:

$6 \mathrm{Na}$ primeira parte intitulada “A emersão da Problemática Ambiental Contemporânea: 0 'Desencontro' entre Desenvolvimento e Meio Ambiente", o diálogo está centrado no despertar contemporâneo da questão ambiental - aqui denominada "problemática" devido à sua complexidade analítica. Torna-se mister uma análise criteriosa de trabalhos que, de forma pessimista, indicavam um futuro nebuloso para a sobrevivência humana na Terra. Destaca-se a obra Limites do Crescimento (ou Relatório Meadows), que serviu de base para a Conferência das Nações Unidas sobre Meio Ambiente Humano, realizada em Estocolmo, no ano de 1972. O Relatório Meadows colocava em xeque a noção de crescimento econômico e evidenciava as contradições Norte-Sul, com a opção dos países do Terceiro Mundo pela conquista do desenvolvimento ainda que com o anátema da poluição. Esta celeuma entre "desenvolvimento a qualquer custo" versus "crescimento zero" influenciou diretamente a Conferência de Estocolmo, na qual a diplomacia brasileira - sob as hostes do desenvolvimentismo característico do período da Ditadura Militar e o consequente 
processo de espoliação das riquezas naturais - teve posição bastante firme, com atuação destacada contra mecanismos de controle do crescimento.

7 A segunda parte, com o título "Neoliberalismo e Meio Ambiente: Por uma politização da Crise Ambiental", trata da estigmatização do mundo pela Crise Ambiental, uma verdadeira fortaleza conceitual erigida por autores de diferentes filiações teóricas, mas geralmente criticada sem que se atinja o cerne do problema: o uso da natureza enquanto mercadoria. Esta noção de natureza-mercadoria atinge seu corolário no documento chancelado pela ONU intitulado Nosso Futuro Comum (ou Relatório Brundtland), que propugnou a concepção de desenvolvimento sustentável como "redentora dos males da humanidade" e acabou por influenciar a Conferência das Nações Unidas sobre Meio Ambiente e Desenvolvimento, no Rio de Janeiro em 1992. Se vinte anos antes, o Brasil Militar projetou-se como um símbolo da crítica mordaz sobre a "limitação do crescimento", o Brasil Neoliberal, então presidido por Fernando Collor de Mello (que sofreria o impeachment por corrupção meses depois da conferência) tornou-se sede da nova conferência, e, por conseguinte, palco de celebração do desenvolvimento sustentável em escala global.

Por fim, a terceira parte, denominada "A Conferência do Rio de Janeiro (Rio-92): entre a ideologia e a utopia", é o momento em que se analisa a Conferência do Rio de Janeiro - 1992 como um simulacro. Entre as proposições dos "especialistas" - aqueles que detêm o discurso competente (CHAUI, 1982) pelas diplomações e títulos acadêmicos, mas que se colocam como porta-vozes dos interesses dominantes - e a efervescência dos movimentos sociais durante o Fórum Global, a Conferência do Rio de Janeiro institucionalizou o desenvolvimento sustentável, com a assinatura da Agenda 21 e a promoção do neoliberalismo ambiental. Entretanto, apontamos que nos interstícios das ações dominantes em prol da Operação Desenvolvimento Sustentável, emergiram espaços de esperança, em torno das novas utopias criadas pela construção de uma sociedade melhor. $O$ diálogo entre a celebração de um consenso ou a gênese de novos dissensos é o alvo central deste capítulo final. Após as considerações finais, que objetivam fazer um breve balanço de vinte anos do processo de celebração do desenvolvimento sustentável enquanto ideologia e geopolítica, há um epílogo intitulado "Rio + 20: A concepção de "Economia Verde" e a retomada da Ideologia do Desenvolvimento Avassalador", que permite realizar uma leitura geográfica do contexto territorial global e local desta conferência, enquanto resultado de vinte anos de consolidação do desenvolvimento sustentável, que assumiu seu viés econômico através do termo "Economia Verde". A "Economia Verde", celebrada na Rio + 20 como aprofundamento do desenvolvimento sustentável, revelou com constrangedora clareza o quão o desenvolvimento, esta palavra-força que amalgama crescimento econômico e modernização produtiva, era o centro do debate. Isto explica em parte o declínio dos cuidados ambientais de diferentes governos que emergiram no período. 


\section{AUTHOR}

\section{LEANDRO DIAS DE OLIVEIRA}

Professor de Geografia Econômica do Departamento de Geografia e dos quadros permanentes do Programa de Pós-Graduação em Geografia e do Programa de Pós-Graduação Interdisciplinar em Humanidades Digitais da Universidade Federal Rural do Rio de Janeiro (UFRRJ). Correio eletrônico: ldiasufrrj@gmail.com. 